\title{
TEATRAS FEMINISTAS, SUBSTANTIVO FEMININO PLURAL: TRABALHO-DE-MEMÓRIA SOBRE AS NARRATIVAS DO FEMINISMO NO TEATRO BRASILEIRO
}

\section{Lúcia Regina Vieira Romano}

Universidade Estadual Paulista Júlio de Mesquita Filho (UNESP)

\section{RESUMO}

O ensaio propõe a reconstrução do encontro presenciado pela autora entre Amelinha Teles, Cláudia Schapira e Fernanda Azevedo, promovido pelo SESC Belenzinho e ocorrido no bojo das comemorações de 8 de março de 2016. A memória é empregada como método, inspirando-se no trabalho da socióloga alemã Frigga Haug (1992, 1996), em suas considerações sobre o trabalho detetivesco que toma como ponto de partida a experiência real das pessoas no mundo e a teoria marxista de exame das condicionantes materiais, discursivamente evocadas pelas mulheres. Observo, desse modo, as práticas de gênero na área do teatro brasileiro num enquadramento amplo, em que atuam as políticas de identidade, os papéis sociais, os feminismos e as modalidades de criação e produção teatrais, num arco histórico de cerca de 50 anos. A retomada do ano de 2016, portanto, lança mão do método de trabalho-damemória a fim de aplicá-lo ao exame da construção social de gênero feminino no teatro, assim como para convidar à revisão em ato, em 2018-2019, desse processo e das estruturas históricas envolvidas, buscando apontar aqui as contradições que as tornam móveis e mutáveis.

Palavras-chave: $A(r)$ tivismo feminista. Teatro e feminismo. Teatro feminista brasileiro. Trabalho-dememória. Frigga Haug. 
os últimos dias, ${ }^{1}$ tenho me arrastado entre os eventos da vida ordinária, dividida entre as angustiosas notícias sobre o Brasil que recebo pelo ZAPP - esse demônio da (sub)comunicação que entrou no corpo do meu celular há quatro meses e que, desde então, me fez refém e hoje ameaça minha sanidade - e as inúmeras convocações de mobilização urgentes, sob um céu que vai pesando e pesando, avisando "tempestade, tempestade, tempestade". No meio disso tudo, estamos aqui nessa mesa temática para conversar sobre artivismo no teatro, ao lado de artistas mulheres, entre muitas outras que mereceriam igual privilégio de serem ouvidas por vocês sobre a união entre as ações teatrais com intervenção política. Com certeza, elas não deixariam de fazer jus ao destaque que nos foi oferecido. Enfim, o que valeria a pena ser dito sobre como as estratégias artísticas podem sensibilizar a sociedade, convidando a todas e a todos a problematizar a forma como vivemos e convivemos, provocando maior engajamento social, processos criativos renovados e uma cena mais subversiva e inquieta, num momento como este?

Bem... quando estamos aflitas, são os amigos e amigas que nos reconfortam. São também nossas companheiras as ideias de que gostamos e as maneiras de ser e estar em que acreditamos e que nos constituem como indivíduos. É deste modo que entendo o trabalho com $A$ teatr $A^{2}$ feminista que iniciei em 2005 , talvez antes. A teatrA feminista é uma modalidade de artivismo que alimenta um olhar crítico sobre as relações entre as pessoas, para intervir artisticamente - poeticamente e performativamente - no campo social, a fim de diminuir as desigualdades que levam a marca de gênero. A teatrA feminista é também um caminho de aprendizado, o qual persigo, mesmo avaliando continuamente se o feminismo na cena abre uma via de reflexão sobre o fazer teatral, ou se este fazer me escapa quando busco vivê-lo pelo viés do feminismo. Alguém da plateia poderia objetar: "Afinal de contas, que teatro seria este, incapaz de aceitar a sua tomada de posição como mulher e artista?".

Contemplada pela certeza contida nesta dúvida, responderia que há um impulso totalizante nos teatros e que os feminismos constituem exatamente um tipo de pensamento em ação que, de certo modo, é uma crítica a um teatro que se diga totalizante. Desde 2005, talvez antes, encontro no teatro feminista um outro teatro, por isso, umA teatrA, capaz de mobilizar o todo daquele teatro conhecido, porque provoca seus contornos majoritários, ou melhor, demonstra os limites do seu discurso e o que ele, como qualquer outro discurso, deixa às margens e denomina como "de fora". Portanto, minha identificação com a epistemologia feminista dá-se

\footnotetext{
1 O presente artigo foi apresentado em versão resumida no Congresso ABRACE 2018, em Natal, na Mesa "Vozes feministas: Arte e Ativismo". A apresentação do texto contou com as intervenções de Melissa dos Santos Lopes, Maria Brígida de Miranda, Verônica Fabrini e do público presente, também autoras e autores indiretos do debate aqui proposto. Na ocasião, fomos movidas pela citação de As Bacantes, de Eurípedes, trazida por Brígida de Miranda: "Dioniso às Bacantes: 'Ó mulheres bárbaras, que pânico vos tomou, para que estejais prostradas por terra? / Ao que parece, sentíes que Baco abalava o palácio de Penteu. / Vamos! Erguei vosso corpo e repeli de vossa carne o pavor, tende confiança!"'.
}

2 Agradeço o mote dA teatrA, aqui desenvolvido, à pesquisadora e professora Dodi Leal, em conversa informal na Abrace 2018. 
porque ela expressa minha sensação de incompletude com o teatro, o mundo e seus contornos hegemônicos, movendo minha experiência e permitindo o (auto) questionamento.

Em virtude dessa minha persistência, os feminismos e A teatrA feminista ocuparam a posição de meu "ZAPP de gênero": sou provocada pelos feminismos, que apressam meu contato com as outras pessoas e possibilita estreitar minha comunicação com elas. A teatrA feminista, por sua vez, tem me auxiliado a fazer o velho teatro morrer em mim, deixando emergir, sempre, uma novA TeatrA aberta para o mundo, emprenhada de resistência, pulsante mesmo quando parece que não temos estratégias artísticas e políticas suficientes para interferir nas emanações terríveis de um céu cinzento desabando sobre as nossas pequenas cabeças. Tempestade, tempestade.

Por causa dA teatrA feminista, também venho encontrando outras artistas e pensadoras $d A$ teatrA, que foram tecendo comigo uma perspectiva - porque um olhar sozinho não faz verão, quero dizer, não faz um horizonte de visão. Então, feminismo \& A teatrA feminista não são um tema, mas uma turma, uma tentativa de fala composta, ainda que cheia de diferenças internas; $A$ teatrA feminista é uma dentada coletiva no corpo do Teatro, útil para quem não aspira a uma refeição solitária.

Pois que em 8 de março de 2016, convidada por uma curadoria que me viu como artista de teatrA e pesquisadora de teatrA feminista, fui chamada para mediar uma mesa no evento Arte substantivo feminino, no SESC Belenzinho.

Permito-me um aparte, a fim de dimensionar o sentido deste convite. As comemorações de 8 de março costumam causar em mim uma impressão dúbia. Por um lado, me agrada que se busquem formas de homenagear as mulheres e o esforço daquelas que dedicam seus dias para a melhora das relações entre as pessoas e, em especial, pela maior visibilidade às questões que limitam nossa liberdade e expressão. Também me agrada que essa homenagem escolha como data significativa o dia que, em 1857, trabalhadoras protestaram em Nova York contra as péssimas condições de trabalho a que eram submetidas - embora outras explicações concebam o dia de 8 de março como tendo sido resultado de uma criação do Partido Socialista estadunidense, em 1908.

Seja este ou aquele caso o motivo da efeméride, a data tornou-se uma oportunidade de reunião entre mulheres e outrxs interessadxs na defesa da igualdade, ou seja, contra a desigualdade que favorece os homens, em detrimento das mulheres. O dia 8 de março é, então, um dia de honra à luta das mulheres e às mulheres que se colocaram à frente de seu tempo, de tal forma que sua ousadia (a palavra não é exagerada, tendo em vista a violenta repressão a que acabam estando sujeitas quando se insurgem) seja reconhecida e perpetuada.

Ao mesmo tempo, sabemos que é inútil um dia da mulher, contra trezentos e sessenta e quatro dias dos homens. É difícil dizer o que soa pior: que ainda exista tanta disparidade entre os valores atribuídos aos feitos dos homens e aos das mu- 
Iheres, de modo que um dia delas ainda se faça necessário, ou que eles continuem ocupando a posição do privilégio. A que se pode oferecer luz em um só dia, contra tantas outras ocasiões de apagamento? Homenagens póstumas podem efetuar alguma mudança no tempo presente? Talvez devêssemos proclamar, frente a este contexto, "viva o último dia da existência ainda necessária do dia das mulheres!". E, assim dito, partir para a ação imediata, fazendo concretizar-se o grito de "basta!".

Entretanto, quando são as mulheres que tomam a frente dos eventos de 8 de março, já ouvimos soar uma voz que a mera "comemoração" tende a emudecer. É o caso da Marcha Mundial das Mulheres, que toma as ruas desde 2000 e que, a exemplo da Marcha Pão e Rosas canadense, ocupa o espaço público com uma manifestação coletiva liderada pelas mulheres, demonstrando em ato as reivindicações urgentes. Nesse caso, não há uma instituição que dita o formato de memorabilia, mas assume-se um caráter de presentidade num gesto de protesto. As caminhadas, as paradas de rua com esse caráter e suas derivações são ações solidárias de mulheres que se colocam "em marcha", literalmente, para não permitir que a luta feminista seja matizada por outros discursos que sustentem a submissão do gênero feminino. Rocha e Azevedo (2014, n.p.) esclarecem:

Neste 8 de março de 2014, construímos o \#8Feminista. Nós, mulheres em marcha, fomos para as ruas para dizer qual é o real propósito deste dia: continuar lutando, como sempre fizemos, por liberdade, respeito e igualdade. Fomos e vamos às ruas porque queremos que nossa voz seja ouvida, que nossos corpos deixem de ser violentados física e simbolicamente, que queremos participar das decisões que dizem respeito à vida pública e, portanto, à vida de cada uma de nós.

Maior contrassenso ainda ocorre com as homenagens artísticas que o dia suscita. 8 de março acabou sendo um dia para se agendar todo tipo de espetáculo, oficina, exposição e palestra que tenha por tema a "mulher". Mais uma vez, o problema não reside na maneira como esse "tema" é interpretado pelas programadoras e programadores, visto que nunca é tarde para pensar a produção por meio de um olhar mais sensível ao gênero das criadoras e das espectadoras, mas pelo fato de que a existência dessa agenda acaba por "apaziguar" as tensões que giram em torno do problema da equiparação de oportunidades (também) nas artes, assunto longe de ser superado nesta área, assim como nos demais campos da cultura.

Beskow (2017) demonstra, em um estudo dos guias de teatro da cidade de São Paulo, como o assunto funciona no processo de difusão, no momento em que as peças de teatro chegam aos espectadores e espectadoras: dos quatro guias consultados (selecionados entre aqueles de grande circulação na capital), ao longo de 21 meses, $100 \%$ deles apresentam mais trabalhos feitos por homens, seja na composição dos coletivos, na direção ou na produção. Duas hipóteses poderiam ser verificadas: a primeira, que as mulheres fazem mesmo menos teatro que os homens; a 
segunda, que elas continuam invisibilizadas. Ainda que empiricamente (pois a falta de dados dos guias pode gerar distorções nos resultados finais), a pesquisadora conclui que as produções de homens e mulheres tornam-se desiguais no estreitamento do gargalo, ou seja, quando a peça vai ser divulgada e comercializada. Também nota que nas editorias dos guias em quadro, a maioria dos responsáveis pelas seleções das peças do menu representa o sexo masculino.

Bem, alguém poderia reclamar que um jornalista ou uma jornalista escolhe $o$ melhor, segundo os critérios praticados pelo veículo em que trabalha; assim como que uma obra teatral pode ser boa ou má, seja ela assinada por um homem ou por uma mulher. Mas é impossível afirmar que a clivagem de gênero não esteja operante, uma vez que a construção social de gênero permeia todas as formas culturais, incorporada no meio teatral segundo o "molde interpretativo do patriarcado" (Muniz, 2015, p. 327). Numa reversão do mesmo movimento, é exatamente a lógica binária que entra em funcionamento na programação festiva de 8 de março.

Outra contradição nesta integração $\mathrm{dA}$ teatr $\mathrm{A}$ às festividades do dia 8 diz respeito à natureza do evento teatral, de abrangência (em termos do público) mais restrita do que uma manifestação massiva de rua. De fato, uma sala de espetáculos lotada não costuma ser numericamente comparável a um grupo de pessoas ocupando uma via ou uma praça da cidade. Pesa a nosso favor, por outro lado, que há nas artes performativas um tipo de concentração que compensa qualitativamente a restrição do total de participantes. Assim, é possível considerar até mesmo uma mesa de debates um tipo de partilha útil para fomentar insurgências a favor de, nos termos de Rocha e Azevedo (2014), mais "liberdade, respeito e igualdade" para as mulheres.

Enfrentando estes dilemas e organizando-se diferentemente de outras homenagens que já vi acontecer no mês das mulheres, o evento Arte substantivo feminino iria de janeiro até 9 de abril e reuniria eventos variados, resultando que o dia 8 (o dia "da mulher") prometia ser mesmo uma ocasião (e não a única) especial, integrada a um conjunto de encontros plurais, tendo a mulher como protagonista. Também a diversidade das ações reunidas no Arte substantivo feminino permitiria que somássemos nossas colaborações, confrontando posições e questionamentos trazidos pelas artistas da cena, pensadoras, ativistas, professoras, escritoras e outras tantas feministas e curiosas que comparecessem às atividades. Seriam muitas pessoas diferentes, que eu desejava encontrar. Aceitei o convite.

No entanto, retomo aqui o encontro de março de 2016, não apenas por ter sido uma ocasião memorável, mas porque aquele dia ilumina o hoje. Ali, compartilhando da experiência das debatedoras convidadas, Maria Amélia (Amelinha) Teles, Cláudia Schapira e Fernanda Azevedo, compreendi alguns aspectos da trajetória feminista nA teatrA nacional cabíveis para pensarmos os impasses do artivismo feminista na nossa produção cênica atual, diante das novas forças que atuam na coletividade. Gostaria de retomar o contexto de atuação militante e artística dessas mulheres, a fim de confrontar a sensação de falibilidade e impossibilidade que nos ronda agora, parecendo extrair da nossA teatrA seu poder de fogo. O que pôde A teatrA feminista dos anos 1960-1970 em diante e o que ainda pode em tempos como estes? 
Para compreender os nós das relações de dominação e sujeição que nos aprisionam, proponho pensarmos as transformações históricas dA teatrA feminista no Brasil, tecendo uma costura entre gênero feminino, criação artística em teatro e a sociedade brasileira. Frigga Haug, socióloga marxista e feminista alemã, foi quem nomeou essa metodologia de "escavação" como trabalho-da-memória (Erinnerungsarbeit). Haug sugere que a análise de um fato social - como, por exemplo, a virada na situação das mulheres empreendida pelo feminismo ou as mudanças na visão da sociedade sobre as lutas das mulheres - requer a quem pesquise os eventos tanto da compreensão dos seres humanos como produtores das circunstâncias, do entendimento sobre eles mesmos e da história quanto das contradições presentes nos próprios fatos, imersos numa relação de forças que incluem os gêneros e a produção (ou, o capital). Sim, a influência de Haug é o marxismo, mas ela considera também práticas e teorias favoráveis às mulheres, segundo ela, obscurecidas na formulação da teoria marxista-leninista, em virtude da dominância do ponto de vista masculino (inclusive, do próprio Marx).

No trabalho-da-memória, é preciso buscar relatos que demonstrem como a socialização (ou a construção social das forças da ideologia) emerge na forma de um determinante do processo que analisamos. Depois de resgatados, os relatos são revistos coletivamente, ou seja, são reescritos, trazendo à baila as lacunas, os momentos em que a emoção de quem contou se sobrepôs em excesso ou em que os clichês dominaram sua versão da história. A partir dessa revisão crítica coletiva, temos a matéria de observação mais viva, pulsante e ancorada no meio social.

A respeito do fazer teatral das mulheres permeado pela perspectiva do pensamento e prática feministas, os relatos de Maria Amélia Teles, ${ }^{3}$ Cláudia Schapira e Fernanda Azevedo, presentes à Mesa de 2016, resumem a visão de três gerações de mulheres num arco histórico de cerca de 50 anos. Esses relatos nos permitem analisar como a questão continuou em movimento, assim como atualizar a multiplicidade das práticas de gênero no teatro brasileiro, num enquadramento amplo, em que atuam as políticas de identidade, os papéis sociais, os feminismos e as modalidades de criação e produção teatrais. Não há entre essas três mulheres um padrão único, mas percursos distintos e, aparentemente, desconexos no que concerne à dupla arte-sociedade. As experiências subjetivas delas, no entanto (assim como a minha própria), funcionam como demarcadores temporais e simbólicos de relações sociais que elas testemunharam e ajudaram a construir e destituir, ao mesmo tempo que as relações materiais constituíram suas subjetividades e ações no mundo (e nA teatrA). Representam, conforme resume Carter (1999, p. 14), "uma ponte para alcançar a lacuna entre 'teoria' e 'experiência"', apontando para sugestões de como as mulheres tomaram conta (o quanto puderam) de suas escolhas artísticas e políticas.

Sublinho que minha escavação e elaboração não se restringem apenas ao ocor-

3 Feminista "histórica", Amelinha Teles tem a presença carregada de uma qualidade temporal singular. Se somos todas sujeitos da história, ela tem dentro de si tantas histórias, tantas personas, que sua pessoa dá relevo absoluto ao aqui-agora, portando o acúmulo do passado e um devir muito vivo. 
rido no encontro Arte Substantivo Feminino, mas projeta-se para o percurso conseguinte dessas artistas e do campo teatral, estabelecendo uma cooperação também entre tempos e espaços diversos, numa continuidade não linear das considerações postas à mesa naquela ocasião. O trabalho-de-memória aqui exercitado, desse modo, envolve outras falas das mesmas autoras, posteriores à nossa conversa presencial, acrescidas com o cuidado de não distorcer autorias e orientações.

Como a memória se faz de vácuos, recordo-me pouco do que eu mesma falei sobre o tema proposto pela curadoria do evento, "O Feminino na Arte e na Sociedade". Mas três afirmações marquei em destaque no meu caderno de notas, uma de cada integrante da mesa. Amelinha Teles, advogada e ativista feminista das mais emblemáticas, em certo momento, confessou: "Hoje, vou ao teatro como espectadora, mas muito raramente". Cláudia Schapira, artista de teatro inquieta e progressista, comentou: "Eu reluto em caracterizar o feminino e o feminismo como um mote fundamental, mas reconheço a força das mulheres na minha cena"; enquanto Fernanda Azevedo pontuou, a uma boa altura da conversa: "Gênero pode ser uma das estratégias de reunião entre as trabalhadoras da cena". Essas frases contrastantes, marcantes em 2016 e ainda significativas, desenharam um quadro do projeto de construção de um teatro de importância social e de cunho feminista no Brasil, evidenciando a flutuação entre crença e descrédito que o tem caracterizado.

Maria Amélia Teles, no mapa espaço-temporal que retrato, corresponde a uma geração de feministas que inicia seu engajamento nos anos 1960-1970. De formação de esquerda, em decorrência do Golpe Civil-Militar de 1964, entra em contato tanto com a mobilização das mulheres quanto com as ações de resistência à suspensão súbita do Estado de direito. Este é um dos traços peculiares do feminismo dos anos 1960-1970 no Brasil: a experiência da ditadura determinou a extinção dos partidos e organizações de esquerda e atingiu também os movimentos das muIheres, mostrando-se como uma forma particularmente sádica das opressões de gênero na tortura contra as mulheres presas pelos militares. Ex-militante do PCdoB (em 1987, foi expulsa do partido - "Tentei muito discutir feminismo com o PCdoB", ela resume em entrevista de 2013), ${ }^{4}$ Maria Amélia de Almeida Teles foi presa em 1972 pela Ditadura junto com seu marido (falecido em 2015), uma irmã grávida e os filhos pequenos. Os três adultos foram torturados pelas forças da repressão. ${ }^{5}$ Recentemente, suas memórias foram postas em dúvida em manifestações da direita, que tentaram negar os fatos já comprovados.

Costuma-se atribuir a essa geração, em termos dos movimentos feministas, a pertença a uma "segunda onda" feminista (assim caracterizada tanto no Brasil

\footnotetext{
4 Teles apud Oliveira (2013).

5 A narrativa do modo como as crianças foram expostas ao sofrimento dos pais é estarrecedora. Para exame mais completo, consultar os registros dos processos no TOMO III - As ações judiciais das Famílias Teles e Merlino. In: COMISSÃO DA VERDADE - SP. TOMO I. Disponível em: http://comissaodaverdade.al.sp.gov.br/ relatorio/tomo-i/parte-iii-cap3.html. Acesso em: 24 set. 2018.
} 
quanto fora dele com fins didáticos), com especificidades locais e até mesmo com variações dentro do país. No caso de Amelinha Teles, sua militância reflete ainda um momento de diálogo entre os feminismos e o marxismo no Brasil (sem negar a tensão entre eles), assim como o cerceamento do fluxo entre esses movimentos de esquerda (e deles com a sociedade mais ampla), em razão da ilegalidade a que os movimentos sociais foram logo conduzidos pelos atos governamentais que institucionalizaram o controle e a repressão.

Por sua vez, Cláudia Schapira, artista multidisciplinar, formou-se como atriz na EAD (Escola de Artes Dramáticas da USP, em São Paulo) no final da década de 1980 e passou a atuar como encenadora, figurinista e dramaturga, assumindo a liderança de um grupo teatral próprio, o Núcleo Bartolomeu de Depoimentos, em 2000. Seu acercamento com o "universo feminino", ou uma "escrita feminina", seria para ela o traço de aproximação com o feminismo, mas sem estabelecer uma relação direta com os movimentos das mulheres ou mesmo com a epistemologia feminista. Isso a torna um exemplo de outra geração: herdeira das "feministas históricas" ${ }^{\text {da }}$ segunda onda, que no ambiente teatral assumiu posições destacadas, mas não entendeu de imediato a luta feminista como sua aliada. Esta geração, contrariamente, pareceu compactuar com a ideia, disseminada ao longo das décadas posteriores ao Golpe de 1964, de que as feministas não mereceriam atenção e crédito, pois eram ressentidas e desqualificadas, assumindo o discurso alimentado por uma campanha amplificada pelas mídias de massa, que ressoava a mediocrização das mulheres como um todo.

O que se desdobrou na vivência da geração de mulheres à qual pertence Cláudia Schapira, na fase intermediária entre a segunda e a terceira ondas feministas, não cabe num resumo simplificado, merecendo um recuo histórico maior para sua compreensão. No contexto do Brasil, a "segunda onda" foi ganhando forma entre os movimentos de mulheres ligadas aos grupos políticos e estudantis de esquerda nos anos 1960, lideradas pelas intelectuais e artistas que conheceram diretamente grupos e pensadoras feministas norte-americanos e europeus, assim como pelas muIheres militantes relacionadas à igreja católica e aos movimentos populares (Zirbel, 2007). Herdeiras da inclusão da mulher no espaço público, por meio do ingresso no mercado de trabalho e das circunstâncias favoráveis à sua emancipação nos anos 1950 (entre elas, o enorme crescimento das cidades, a amplificação do acesso ao ensino e a constituição de uma consciência de direção individualista), as feministas logo sentiram no Brasil o peso da contrarrevolução que vinha conter o impulso que,

6 Ser feminista histórica quer dizer que feminismo, para essa geração, é história de vida. Amelinha relata que em Breve história do feminismo, escrito por ela, realiza uma análise dos eventos que de fato viu acontecer ou que marcaram sua pele. Também é autora de Da guerrilha à imprensa feminista: a construção do feminismo pós-luta armada no Brasil (1975-1980), em coautoria com Rosalina Santa Cruz Leite, desta vez, sobre sua participação na imprensa feminista, em especial nos jornais Brasil Mulher e Nós Mulheres, já nos anos da anistia política. São obras que narram sua vivência na militância feminista e que nos ajudam a compreender o relacionamento, algumas vezes tenso, entre as feministas e o comunismo. 
nos Estados Unidos e em grande parte da Europa, deu espaço para a contracultura e para as conquistas no campo dos direitos humanos.?

Após o chamado "distensionamento" político, já em meados dos anos 1980, a atuação das mulheres na vida social brasileira amplificou-se, ao mesmo tempo que os feminismos distanciaram-se dos movimentos de base, encontrando acolhida na Academia e na política institucional (naturalmente, nos partidos de esquerda e centro-esquerda). O retorno a uma associação com movimentos sociais e artísticos mais heterogêneos (em termos de classe social, raça-etnia, formação e geração) coincidiu com a reconstrução das instituições políticas e da liberdade de expressão no país, assim como com uma inclinação dos feminismos para a revisão da categoria "mulher", na direção de uma identidade menos essencialista e de uma classe das mulheres mais plural. A emergência de outros grupos identitários e a ênfase numa visão mais relacional do gênero, por sua vez, abriram espaço para o fortalecimento das narrativas sobre interseccionalidade, identidade fluida e para os estudos queer e de masculinidade, já na crista da terceira onda do feminismo.

Integrante de uma geração um pouco mais jovem que a de Schapira, seria menos acertado conceituar a produção de Fernanda Azevedo como "feminina", ou "da mulher", do que "feminista". Assim, não parece fugir da certeza, como afirma Teles (apud Oliveira, 2013), de "[...] que feminista nunca está na hora certa e no lugar certo. Nós sempre incomodamos" (Teles apud Oliveira, 2013, s.n.). Atriz, formada no Rio de Janeiro e atuando profissionalmente em São Paulo desde 2006, junto à Kiwi Cia de Teatro, em $2009^{8}$ já militava em coletivos feministas e grupos de mulheres. Muito embora pertença a um grupo teatral "misto", foi neste coletivo que criou a peça Carne, patriarcado e capitalismo, que começou a circular em 2008 e trata do tema da violência (simbólica e física) contra as mulheres brasileiras, discutindo as raízes dessa violência no patriarcado e no capitalismo. Na forma de teatro-documentário, Carne é formada por fragmentos que entremeiam narrativas e cenas dramáticas.

Esta última geração aqui esboçada pôde desfrutar da metamorfose da sociedade brasileira (onde se inclui a chegada ao poder de um governo de caráter mais esquerdizante, após 2003) e do investimento de luta das gerações anteriores de ativistas. Quando em mobilizações mais recentes o Brasil foi surpreendido pela presença de mulheres muito jovens nas ruas, mobilizadas também pela interatividade

7 Esta renovação dos costumes vinha misturada a um projeto de transformação social, em termos de uma revolução socialista (ainda que a crise dos regimes socialistas estivesse também em curso) que foi determinante no feminismo nacional, um país de enormes desigualdades sociais, evidentes nos anos 19601970.

8 Em 2009, Carne destacava-se num panorama de outros poucos exemplos reconhecíveis de ação feminista no teatro, entre eles, a Cia Atuadoras, com o espetáculo Mulher a vida inteira (direção de Renata Zanetta e texto de Ana Roxo, de 2008), a Cia Mal Amadas, liderada por Marta Baião (no interstício entre teatro profissional e artivismo não profissional), e montagens pontuais, como, por exemplo, Gato Sem Rabo, de Alice Ke Celso Cruz (criação de Lúcia Romano baseada em Virginia Woolf, estreada em 2006), acompanhada do Projeto Mulheril (realizado na Caixa Cultural, também em 2006). 
virtual, o que aconteceu não foi apenas uma explosão pontual, mas o resultado de ações menos visibilizadas, mas profundas e continuadas. Na conhecida "primavera feminista" de 2015, que se alimentou também dos protestos de 2013, constatou-se a disseminação de coletivos feministas e de pautas singulares, com o ingresso nos movimentos de meninas negras, lésbicas, indígenas, trans e pobres, que se unificaram na consciência de opressões cotidianas contra as mulheres, de natureza estrutural, conjugadas às formas de violência física e simbólica ainda praticadas nas periferias, nas faculdades, nas casas e assim por diante.

$\mathrm{O}$ ativismo que Fernanda Azevedo expressa, ao lado de mulheres mais jovens do que ela, carrega um debate que atinge um público maior com uma pluralidade de pautas, gerações e experiências. Sua dificuldade reside na elaboração de questões representativas para todos, sem homogeneizar as diferenças, além de fortalecimento dos laços presenciais (Mota, 2017) - isso sem considerarmos o desafio que significa o cenário atual de avanço do neoliberalismo, do fundamentalismo religioso, da violência policial e paramilitar e de modalidades de cerceamento jurídico-repressivo.

Se os feminismos da geração de Amelinha Teles, embora reunissem linhas de ação diferentes, definiram-se a partir de direcionamentos que poderiam ser caracterizados por uma corrente mais marxista (chamada de feminismo socialista, ou marxista), ao lado de outra mais liberal (que nos anos 1960 era denominada de radical), os feminismos mais "recentes" - entre eles, o "novo" feminismo liberal (este, no sentido de um direcionamento menos esquerdizante) - têm por companhia as denominações de feminismo negro, feminismo interseccional, feminismo lésbico, ecofeminismo e transfeminismo. Entretanto, mesmo essas nomenclaturas, que oferecem uma perspectiva útil para visualizarmos a diversidade de tendências que podem ser contempladas pelos movimentos das mulheres, determinando suas questões centrais e escolhas nas formas de intervenção, são superadas pela tendência das militantes do século XXI de agirem com maior autonomia em relação aos agrupamentos políticos.

As jovens militantes seguem antes um traço de "desterritorialização" (Muniz, 2015) do que as grandes articulações representadas pelas correntes de pensamento feminista, algumas de vertente utópica (Mota, 2017). Sua pertença às classes sociais menos favorecidas e a localização geográfica distante dos centros possibilitam uma ação mais próxima da "vida real" das mulheres negras e periféricas com criatividade ímpar. São alterações, por fim, que testemunham ser o feminismo uma teoria crítica de fundamento histórico, que não se pretende imutável nem ausente de autocrítica, portanto, modificando-se segundo as pessoas e as necessidades do ambiente (na conjunção entre corpo e cultura).

Não é simples traçar uma relação entre os fluxos do contexto histórico, a produção cênica e a teatrA, mas recorro mais uma vez às experiências e aos relatos das palestrantes de Arte Substantivo Feminino, em 2016. Amelinha Teles soma muitos desses aspectos que compuseram a realidade da ação das mulheres nos anos de chumbo e ao longo do "distensionamento". Além disso, distingue-se por ter enfo- 
cado a transmissão do feminismo, primeiro por meio da criação da imprensa feminista, com publicações sobre e para mulheres, e ainda, posteriormente, no trabalho com mulheres periféricas e na formação delas no conhecimento de seus direitos. Tal disposição, contudo, parece tê-la distanciado do campo das artes, o que torna interessante, no Encontro de 2016, o fato de ter sido escolhida para representar, de certo modo, toda uma geração de artivistas. Professora de artes quando capturada pela Ditadura, Amelinha Teles distanciou-se da produção artística para encontrar a ação efetiva no campo do Direito, onde se formou, anos depois. ${ }^{9} \mathrm{~A}$ arte foi deixando de ser um ato que a convocava, enquanto as artistas das artes cênicas passaram por um período difuso, onde aparentemente desapareceu o fazer teatral feminista, embora muitas artistas mulheres tenham se dedicado à luta pela manutenção e ampliação de nossos espaços de criação artística de maneira mais individual.

Assim, não é evidente destacar, na geração dos anos 1960-1970, figuras da área teatral cuja produção cênica continuada fosse direcionada para uma visão crítica a respeito dos papéis sociais de gênero, para a revisão dos modos de representação do gênero feminino ou mesmo para nomear criadoras articuladas em torno da valorização das mulheres. Heleny Guariba, Ruth Escobar e Dulce Muniz são teatristas frequentemente mencionadas, ainda que haja outras artistas mulheres atuantes no teatro que colaboraram tanto para o questionamento e ampliação do "lugar" delAs na cena quanto para o emprego da linguagem teatral como ferramenta de intervenção política. Mas suas criações e reflexões seguem sem o merecido destaque, oficialmente esquecidas, processo no qual a grande mídia e a historiografia do teatro colaboraram, obscurecendo certas obras em privilégio de outras, quando não desmerecendo e ridicularizando ações de teor feminista na cena.

Resta-nos a percepção de que as mulheres dos anos 1970 abriram mão do diálogo entre feminismo e teatro, envolvendo-se em obras cênicas menos influenciadas pelas lutas das mulheres. Também não é possível afirmar que o teatro da época tenha sido um espaço de emancipação plena das artistas, ainda que contasse com a presença de muitas delas, em especial, trabalhando como atrizes. É notável que as artistas ocupavam, em sua maioria, posições que não os postos de concentração de poder decisório, como são os de dramaturgia, direção e captação de recursos, até meados da década de 1980. Uma explanação é que esta situação de intérpretes, e não de proponentes das criações, tenha distanciado as artistas dos temas mais diretamente relacionados às suas vivências no mundo. No aspecto das temáticas feministas no teatro, é preciso lembrar que o próprio feminismo brasileiro reagiu ao quadro determinado pelo Golpe Civil-Militar de 1964, estendido até meados de 1985, diante das prioridades determinadas por esse contexto. Portanto, outra hipó-

9 Foi no direito que Teles encontrou ferramentas para debater as necessidades das mulheres num campo mais amplo, da formulação das leis, atingindo um grupo maior de interessadas para a erradicação dos motivos da violência de gênero: o patriarcado, os preconceitos, as instituições regidas pela ideologia do privilégio de alguns sobre muitas. 
tese deriva destes mesmos eventos: que as artistas feministas no teatro se dedicaram à resistência contra a supressão do Estado de direito, sendo engolidas pela luta contra a Ditadura, por um lado, e pela visão priorizada pela historiografia teatral de vertente esquerdizante, centrada no debate de classe social, por outro.

Amelinha testemunha que, no final dos anos 1970, o feminismo “Era muito voltado para a mulher trabalhadora. Falávamos de creches, de salários, das mulheres nos sindicatos e do machismo nos sindicatos. Abordávamos a violência contra as mulheres" (Teles apud Oliveira, 2013, n.p.). Esse feminismo matiza-se a seguir a partir da experiência do exílio, daquelas que, saindo à força do país, se distanciaram dos movimentos populares locais, mas, por outro viés, conheceram a face internacional dos feminismos. Pautas como sexualidade e o corpo, ${ }^{10}$ até então menos centrais, são retomadas com o ingresso nos movimentos das mulheres de outros grupos identitários, que já se anunciavam em meados de 1970 e que se evidenciaram nos anos posteriores. ${ }^{11}$

No teatro, o tema da sexualidade feminina ofereceu às mulheres a possibilidade de retomada da posição de sujeitos das narrativas na cena, reconstruindo um "espaço feminino". Este protagonismo atualizado motivou o espetáculo Homem Não Entra, surpreendente por atingir um público feminino significativo num período em que o teatro "de mulheres" não gozava de grande empatia (também entre as camadas mais populares) e era duramente reprimido pela censura institucional e cerceado pela censura econômica. Desde sua estreia em 1975 até a última versão apresentada, em 1979, Homem Não Entra, espetáculo escrito por Rose Marie Muraro, Eloneida Studart e Cidinha Campos, trouxe para o palco o cotidiano das mulheres, permeado pelos temas do prazer sexual e da sexualidade.

Sobrevivendo como um dos poucos exemplos de teatro feminista dos anos 1970, a obra representa um fenômeno em termos de comunicabilidade, em virtude da criação de um espaço convival, exclusivo para as mulheres, inspirando-se nos grupos de reflexão e despertar de consciência em voga na época (Cruz, 2018). Seu sucesso comercial, entre outros aspectos, deveu-se também ao enfoque acertado num assunto premente entre as brasileiras, tomando a sexualidade das mulheres como fio narrativo do debate sobre "o lugar das mulheres", utilizando-se de uma linguagem ágil e bem-humorada, já explorada pela atriz e jornalista em seus programas no rádio e na televisão: a relação de Cidinha Campos com a plateia só de mulheres lembrava uma conversa pessoal, de cunho confessional, empregando recursos narrativos e comentários que eram dramaticamente encenados, a título de ilustração. Ao final da peça, conforme registrado nos estudos de Cruz (2018), resta-

\footnotetext{
10 Debate mais presente entre as feministas radicais, Amelinha Teles recorda que também assumiu a discussão, por exemplo, no caso dos contraceptivos - a pílula era criticada por ser causadora de problemas físicos, com o excesso de hormônios (Teles, 2015).

11 Esses grupos, como as lésbicas e gays, fortaleceram o movimento feminista brasileiro pós-anos 1970 e são parte do seu alicerce.
} 
va a ideia de que, dentro do seu lar, as mulheres deveriam guiar-se pelo seu próprio desejo, e não pelo esperado delas pela família e sociedade.

Esse desejo, entretanto, limitava-se à expressão do padrão heterosexual, pois o desejo homoafetivo não constava da discussão. Essa outra dimensão da sexualidade feminina permaneceu ausente dos palcos nacionais até a estreia de Violeta Vita, dirigido por Beth Lopes, que teve Cláudia Schapira no elenco, em 1995. Escrito por Luiz Cabral e com concepção e atuação de Cláudia Schapira e Lu Grimaldi, Violeta Vita inaugura a versão nacional das gay plays, que têm em Angels in America (texto do estadunidense Tony Kushner sobre o homoerotismo masculino e o surgimento da Aids) o expoente mais frequentemente citado na mídia e nos estudos de teatro brasileiro.

Mas Violeta Vita, diferentemente de Angels, é um assunto de mulheres, retratando a relação entre as escritoras Violet Keppel Trefusis e Vita Sackville-West, a partir das cartas trocadas entre as duas. ${ }^{12} \mathrm{O}$ olhar para a intimidade entre as mulheres foi o mote da montagem, traduzindo a singularidade desse tipo de relação numa fisicalidade extremada; os corpos das atrizes em interações explícitas e, muitas vezes, de caráter violento. Interessante que na divulgação, ao contrário do esperado, as artistas enfatizam o quanto este é um amor como qualquer outro. Nas palavras de Grimaldi (apud Rocha, 1995): "É um espetáculo que transcende o amor entre duas mulheres porque uma paixão louca qualquer um pode ter". Semelhante tom de homogeneidade na expressão do desejo feminino é adotado por Schapira, quando resume: "Na peça, fica nítido que o mesmo que fascina e apaixona duas pessoas serve para afastá-las depois da conquista" (Schapira apud Rocha, 1995, n.p.). Sobre a singularidade do comportamento homoerótico das mulheres, nada é ressaltado. Mesmo nos comentários críticos, o máximo que se menciona é o fato de Violeta Vita ser uma obra cênica criada por uma equipe composta quase só por mulheres. Segundo Rocha (1995, n.p., grifo nosso), "Não por coincidência, a maior parte da produção foi feita por mulheres, já conhecidas, do teatro". Sugere-se, assim, que o tema sobre o amor entre duas mulheres surge na cena porque a montagem foi comandada por artistas do sexo feminino, sem discutir o lesbianismo em relevo.

Embora Violeta Vita possa ser relacionada ao feminismo lésbico, ecoando os debates de fins do século XX nos campos do feminismo e das teorias queer, a falta de atenção à dimensão temática da homoafetividade e à presença da ótica feminista nos registros sobre estas e outras montagens integradas por mulheres repercute o silenciamento das próprias realizadoras e o preconceito da mídia - mesmo que esta modalidade de intervenção já fosse oferecida na cena e desenhasse certa continuidade, em obras diversas e com um crescente "amadurecimento" em termos do discurso político proferido. Isto implica, ainda, o reconhecimento social de outras práticas e orientações políticas que não apenas o marxismo. No aspecto da sexuali-

12 O romance, que escandalizou a Inglaterra vitoriana de 1918, expondo as amantes ao risco de prisão por lesbianismo (o amor entre mulheres era proibido por lei e, apesar de as escritoras serem ricas e independentes, assumir a paixão publicamente foi ousadia excessiva), resultou em forte pressão social, o que teria levado à separação do casal. 
dade e do desejo, por exemplo, em 2000, Sereias da Rive Gauche, de Vange Leonel, apresentado no CCSP-SP, foi uma montagem mais consciente de sua atuação micropolítica, pois assumiu publicamente o libelo gay feminino e autodenominou-se por teatro feminista lésbico, possibilitando uma via de identificação importante à comunidade gay. Dirigida por Regina Galdino, a montagem, segunda a autora do texto, pretendia-se didática e clara, fazendo um trabalho socialmente e artisticamente necessário no início do novo século (Garcia, 2010).

Aqui, Homem Não Entra e Violeta Vita aproximam-se pois, tanto em 1975 quanto em 1995, suas abordagens da sexualidade das mulheres evitavam reconhecer uma orientação mais radical, seja em termos de posições políticas de gênero, seja de sexualidade, abraçando a denominação genérica "de teatro de mulheres". A generalização significa, ao longo dos anos, o apagamento de um percurso mais evidente para a criação feminista e favorece a relutância das próprias artistas em perceberem a influência dos feminismos e assumirem publicamente a filiação aos movimentos das mulheres.

O contraditório é que muitas artistas que, nas décadas de 1980-1990, negavam essa filiação ao feminismo (como é o caso de Schapira) observavam a reversão de expectativas de gênero nas temáticas das peças, no protagonismo das artistas muIheres e na caracterização das personagens (isso somado ao seu próprio protagonismo na vida e no ofício). "A possibilidade de autorrepresentação é o salto das muIheres nesse tipo de teatro que me interessa", Schapira resume em 2016, replicando certa versão teatral de um pensamento ligeiramente neoliberal, em que a artista da cena empreende a "[...] atitude deliberada de se servir da própria vida como 'matéria bruta' e da paisagem que se habita" (Schapira, 2012, p. 188). Dona de seus artefatos, essa artista origina por si só um locus reflexivo e uma maneira de expor-se na cena que a tornam não mais uma replicante de padrões, mas uma inventora de "universos", completa Schapira.

Pode-se afirmar que Schapira alinha-se ao que Goodman (2005, p. 57, tradução nossa) entende por um teatro feminista "mais extremo em suas demandas e (em tempo) mais sutil em suas táticas", acenando com uma potência de crítica de gênero no teatro que não se situa apenas nos temas tratados na dramaturgia, mas nos elementos da encenação. Entretanto, quando se afasta de uma discussão coletiva sobre as mulheres, em suas múltiplas relações e processos, a ausência de consciência feminista pelas artistas da cena colabora para que as mulheres se enfraqueçam diante das estruturas sociais e de produção teatral, usualmente menos atentas às reivindicações dissidentes. Nessas circunstâncias, feminino e feminismo acabam operando como sinônimos, o primeiro frequentemente substituindo o segundo, que permanece ocultado e quase nunca reconhecido. ${ }^{13}$

13 Entre as novas táticas adotadas, o teatro de cunho feminista do Bartolomeu (ainda que suas criadoras não mencionassem suas obras como feministas) incorporou tanto um conjunto de abordagens da cena contemporânea quanto o alargamento do campo das políticas de identidade. Na montagem de Orfeu Mestiço, de 2012, essa ampliação entenderá a defesa da diversidade por meio do debate sobre raça e etnia, 
Para as artistas de teatro emergentes na cena brasileira dos anos 1980 e consagradas em fins do século XX, o feminismo deixara de ser um discurso assumido, até tornar-se indevido - ainda que fizessem uma criação de escopo feminista, no sentido da conscientização sobre as hierarquias de gênero e da produção pelas mulheres de uma arte inquietante, em confronto com o sistema patriarcal e seus valores. Nos termos de Schapira, a liberdade vivida pela mulher na composição de novas dualidades (abrangendo as dualidades de gênero) comprovava que a sociedade patriarcal da primeira década do século XXI já estaria perdendo forças, tornando o feminismo - como porta-voz dessas reivindicações e mudanças já em curso - desnecessário. Em 2012, no auge da era Lula, Schapira comemora:

[...] Filhos de duas mães e de dois pais [...] Isso já não é uma utopia, é uma realidade. E daqui a pouco vai ser absolutamente cotidiano! Aí vai ser bom mesmo e a tal da igualdade, não mais um direito conquistado, mas uma expressão natural da vida! Utopias futuras... ainda! (Schapira, 2012, p. 189).

Esta visão otimista dos anos 2010, projetando um cotidiano no qual a natural expressão da igualdade teria lugar, seria contradita por Teles (2013), que entendia que a sociedade brasileira ainda não estava preparada para o fim do patriarcado, mesmo num momento político diverso daquele dos anos 1970. Até mesmo num governo de esquerda, a criação de instituições pró-mulheres não significou uma ação efetiva a favor delas. Segundo Teles (2013),

[a esquerda hoje] pode ser mais pragmática, porque não enfrenta essa repressão direta. Por pragmatismo, aceita fazer uma Secretaria da Mulher, mas a lógica é comandada por uma ideologia patriarcal. [...] Estamos no século XXI e, no Brasil, temos uma Secretaria da Mulher que não fala sobre aborto. Direitos sexuais também são direitos humanos. (Teles, 2013, n.p.).

Para a militante, a mudança na política representativa e na organização administrativa ainda precisava atingir a lógica da sociedade, que continuava calada diante de temas controversos, como o aborto. Como representante do campo social, o teatro também evitou o assunto tabu, que tratou, de modo suavizado, por meio de referências indiretas em peças clássicas, como Despertar da Primavera, de Wedekind, ou em encenações da dramaturgia jovem brasileira, como Confissões de Adolescente, de Maria Mariana. Nesse sucesso do "teatro juvenil" dos anos 1990, a experiência encarnada das mulheres não alcança o compromisso de debater os impasses sociais sobre o controle do corpo da mulher ou seu direito a decidir sobre a maternidade:

dentro da geografia urbana. "Sou apaixonada e ao mesmo tempo fruto das misturas, da diversidade, das injustiças, das divergências", resume Schapira (2012, p. 182) sobre a hip-hópera do Bartolomeu. 
Deus foi legal com as mulheres. Deus criou a Lancôme, o absorvente, os espeIhos de bolso, as lixas de unha e uma grande variedade de remédios para a cólica. E Deus viu que isso era bom. Em sua infinita bondade, Deus criou ainda o sutiã tipo efeito push up, as cintas Slim Control e em último caso, a cirurgia plástica. E Deus viu que isso era bom. (Mariana in Espetáculo..., 2009, transcrição nossa).

Sem contestar o senso comum, Confissões de Adolescente reproduzia a propensão de situar a interrupção da gravidez não como foco, mas como mais uma circunstância dentro de um debate múltiplo sobre "jovens mulheres", que adquiria contornos pedagógicos em face da imaturidade da plateia, majoritariamente adolescente, e discursando em nome da saúde, da religião e da moral.

O teatro profissional, alienando-se do assunto, passou a respeitar cordialmente as forças mais tradicionalistas da sociedade brasileira. Por outro lado, no teatro não profissional, a disposição e a posição foram outras. Excetuando-se o ativismo teatral de coletivos feministas - com destaque para o Loucas de Pedra Lilás, de Pernambuco, que em 2003 já discutia também, por meio de intervenções performáticas e encenações, a legalização do aborto seguro e a humanização dos serviços públicos de atendimento à mulher -, a orientação sobre o "direito à maternidade", dominante nos teatros em comunidade e amador, mostrou-se contrária à liberdade de escolha pelas mulheres sobre seu próprio corpo e, moto-contínuo, antagônico à descriminalização da interrupção segura da gravidez. Em torno do ano de 2010, os exemplos do teatro cristão antiaborto multiplicam-se: Gravidez na Adolescência, de Dayana Melo; Os Indesejados, supervisão de Roberto Otaviano; O que se leva da vida é a vida que se leva, da Cia Boa Nova; O Jugo Desigual, adaptação de Catherine Buarque; Semente de Deus, de Leila Regina de Oliveira; \#Galera_ Grávida agora?!, da Cia Gustav Ritter; e Qual é o limite?, de Cleuza Nogueira, são alguns exemplos. Na peça (publicada na rede) intitulada $A$ difícil escolha, de autoria provável de Tamires Nepomuceno, o assunto é debatido na perspectiva evangélica, sem qualquer abertura para outros discursos. É o que demonstra a cena final, em que Rebeca (uma jovem que engravida fora do casamento) é convertida pessoalmente por Jesus, que se despede dela dizendo: "Está perdoada, minha filha. Agora cuide do presente que Ihe dei... A sua vida e a do teu filho!", antes de sair de cena "andando em meio ao público" (Nepomuceno, s.d.).

O teatro cristão, de caráter evangélico, ao que parece, entendeu o protagonismo das mulheres na vida social e a eficiência do teatro como ferramenta de formação das consciências. Assim, dedicou-se a tomar o assunto do aborto como seu, defendendo o direito à vida do feto (e, em consequência, a criminalização do aborto) por meio do drama. ${ }^{14}$ Enquanto este teatro, que pode ser entendido como antifemi-

14 Encontramos registros na internet sobre apenas uma companhia de teatro não religioso que enfrenta as questões da legalização do aborto e da criminalização das mulheres, em 2015. Trata-se do Teatro Quasilá, de Marília. 
nista, ganhou espaço, também se fortaleceram as vozes feministas na cena. Compreendendo a premência desta e de outras pautas pela emancipação das mulheres, Fernanda Azevedo estreou Carne em 2007 (em parceria com Fernando Kinas, também diretor da montagem), incluindo, num vasto quadro de violações de gênero, 0 aborto clandestino, os crimes passionais, os estupros e o sexismo da mídia (Cia Kiwi, 2015). ${ }^{15}$ Sem vacilar em denominar sua criação cênica como um libelo feminista, Fernanda Azevedo estendeu seu artivismo para a dimensão formativa: o processo de Carne desdobrou-se em atividades pedagógicas voltadas para o preparo de outras artistas para a articulação de propostas em torno do papel das mulheres, empregando a arte teatral para a conscientização das opressões de gênero e orientando o desenvolvimento de um teatro de agitação política feminista.

Em 2018, Fernanda Azevedo concluiu seu mestrado, A atualidade do teatro documentário: percurso histórico e estudo do trabalho cênico Morro como um país, em que escreve sobre a produção artística de seu grupo, na exploração do formato de teatro documentário na peça Morro como um país. Continuou na Kiwi e militando nas lutas pelo teatro de grupo e pelas causas feministas por meio dos espetáculos e intervenções urbanas em apoio às manifestações populares. Ela resume:

Porque, se o teatro pode ajudar em alguma coisa, é justamente nesse processo de revelar coisas que antes não éramos capazes de ver. $E$ é através da observação comum e do "pensar junto" que podemos propor saídas para os problemas. Mas estas saídas e ações que vão surgir a partir do evento teatral precisam acontecer também fora do teatro, junto com os movimentos sociais. (Azevedo apud Natarelli, 2014, n.p.).

A disseminação do tema do feminismo entre as artistas mais jovens e o surgimento de novos coletivos teatrais feministas profissionais e não profissionais, a partir da mesma década de 2010, responderam à mesma ampliação do campo do teatro defendida por Azevedo. Desde então, vimos o debate feminista aflorar com radicalidade dentro das salas de aula de teatro, dos festivais de artes cênicas, dos espaços virtuais da internet e das ruas das principais cidades brasileiras. A teatrA levou ao compartilhamento de pesquisas (tentando tornar as fontes mais acessíveis) e de novas criações. Abraçou o debate sobre o "lugar de fala" e sobre as novas diferenciações do sujeito mulher, que incluem a fluidez e a performatividades de gênero - fatores que complexizam a cena e, ao mesmo tempo, derrubam preconceitos que o velho teatro insistia em conservar.

A multiplicação de grupos e obras feministas, em especial a partir de 2012, não deixa dúvidas do sucesso dA teatrA feminista no Brasil contemporâneo. Schapira comenta em 2012 que "[...] a verdade é que estamos vivendo vislumbres de outros tempos!" (Schapira, 2012, p. 188). Coletivos como a Cia Capulanas, Cia Rubro Obsce-

15 O espetáculo teve uma longa carreira e colaborou para fortalecer o espaço do coletivo na cena paulistana. 
no, Mulheres de Buço, As Minas, Sede das mulheres, Desabafo Feminista, Bastardas, Trajetórias Feministas, NAFEM, Mal Amadas, (Em) Companhia de Mulheres, Coletivo Mãe da Rua e Teatro das Oprimidas dividem a cena com muitos outros agrupamentos de artistas que têm por norte a reinvenção da prática teatral feminista. 0 tema "feminismo" segue sendo investigado por artistas da cena, em produções individuais e coletivas afetadas pelo artivismo feminista, em montagens como $A$ casa dos homens (2013), Sangoma (2014), Maria que virou Jonas ou A força da imaginação (2015), Engravidei, pari cavalos e aprendi a voar sem asas (2016), O evangelho segundo Jesus, rainha dos céus (2017), Cabaré ao revés (2018), Carne de mulher (2018), Levante-se (2018), Para não morrer (2018), Mata teu pai (2018), para ficar em alguns exemplos recentes. A essas criações somam-se as redes Vértice, Projeto Madalena (braço nacional do Magdalena Project) e Mulheres do Teatro Brasil. Na universidade, grupos de pesquisa, matérias curriculares, encontros científicos e publicações acompanharam esse processo.

Mais de 40 anos após do "distensionamento", momento sucedido por um governo esquerdizante, apoiado em bases declaradas na proposta de igualdade social (de 2003 a 2016), as transformações sociais aconteceram, atingindo noss A teatrA e favorecendo a presença das minorias e a atenção às suas vozes. A trajetória das três mulheres aqui destacadas, por sua vez, continuou entrelaçada à resistência feminista também nA teatrA. Fernanda Azevedo manteve-se atuante na cena e na pesquisa teatral, criando junto à Kiwi, participando do Cabaré Feminista, ${ }^{16}$ organizando e coordenando oficinas sobre teatro e gênero (a oficina "As mulheres e os silêncios da história" seguiu por diversas cidades do Brasil). Em entrevista de 2018, Azevedo afirma suas prioridades:

[Antes de entrar na discussão do teatro-documentário, é preciso] ter a oportunidade de falar sobre as questões do feminismo. A gente tem muito medo dos ismos. Parece que a gente tem muita dificuldade de assumir alguns posicionamentos. A gente está automatizado, a gente reproduz essas coisas com muita facilidade, por mais que a gente lute contra [...]. É um treino na verdade, um treino que tem que ser diário. $O$ teatro pode ajudar nesse treino também; ele pode ajudar a fazer da gente pessoas melhores, sem dúvida. (Azevedo apud Moreira, 2018, transcrição nossa).

Cláudia Schapira estreou uma série de trabalhos que têm a mulher como vórtice, procurando diálogos de interseccionalidade entre raça e gênero no Núcleo Bartolomeu, e como diretora e autora em investigações performáticas sobre alternativas aos modelos de representação ao teatro tradicional, nas intervenções Mockimpó - Estudo sobre um Homem Comum (2010), Antígona Recortada (2011), 1,

16 Mais informações sobre o Cabaré Feminista em https://casateatrodeutopias.com.br/2018/09/. 
2, 3... Quando Acaba, Começa Tudo Outra Vez (2015), Memórias Impressas (2015), Efeito Cassandra - na calada da voz (2016), para resumir parte desse percurso intenso. Amelinha Teles prosseguiu falando em nome da memória e da verdade, defendendo a importância da apuração e da reparação jurídica dos crimes de Estado cometidos durante a Ditadura, enquanto sustenta novos projetos feministas com mulheres de baixa renda na Grande São Paulo. Com frequência e paciência, mantém-se em contato com as gerações mais jovens de feministas dA teatrA, como fez conosco naquele dia de 2016.

Eu mesma prossegui estudando a ação feminista no teatro, encontrando outras ativistas que, antes de mim, iniciaram o trabalho de reconstrução do tecido da reflexão feminista sobre a cena, esgarçado pelos anos de repressão; de certo modo, correndo atrás do atraso das artes cênicas em relação às pesquisadoras de estudos de gênero, estudos da mulher e estudos feministas, em núcleos de pesquisa e em seus próprios trabalhos acadêmicos.

Com lamento, entretanto, também confirmamos a ausência de programas institucionais para a promoção de umA teatrA feminista. Continuamos a depender de uma mídia que guarda espaço restrito para os novos experimentos das artistas muIheres e compartilhamos a dificuldade de novas pesquisadoras encontrarem fontes atualizadas sobre o artivismo feminista na história do teatro brasileiro, ainda a ser revirada pelas óticas das políticas de gênero e do feminismo. Mais uma vez, demoramos (especialmente, como área de pesquisa) a abraçar os movimentos das jovens feministas, nas escolas secundárias, e da "primavera feminista", nas ruas. O que o fazer teatral poderia ter oferecido a elas para que ampliassem suas ações? O que ainda podemos escutar do que elas disseram e que ainda não conseguimos ouvir?

Em 18 de outubro de 2018, revisado em fevereiro de 2019, o presente relato pretendeu contribuir para o trabalho-de-memória dA teatrA, interpondo as experiências de representantes de três gerações de mulheres brasileiras, reunidas em 2016. Entendo ter sido a ação de ir e vir do tempo histórico aqui realizada uma síntese significativa das possibilidades do feminismo $n A$ teatrA brasileirA: assim como o próprio fluxo da história, as ondas do feminismo quebram na praia desordenadamente, mas conformam um mesmo oceano. ${ }^{17}$ Por fim, este é apenas um primeiro passo de revisão coletiva dos fatos destacados, para dialogarmos e fazermos juntas a reescrita do nosso futuro. Talvez, diante das pautas urgentes dos dias recentes de 20182019, esse recado do passado reativado demonstre como a construção social das forças da ideologia conduzem as mulheres, capturam A TeatrA e nos imobilizam, ou como a ideologia hegemônica pode ser combatida pelas mulheres, mobilizar um conjunto de pessoas e emergir na forma de determinantes do processo histórico.

\section{Referências}

17 Agradeço a imagem do oceano feminista, aqui reproduzida, a uma conversa com a atriz e pesquisadora do feminismo e dA teatrA, Luciana Lyra, em setembro de 2018. 
BESKOW, Daniela Alvares. O discurso das mulheres na cena paulistana de 20152016: uma proposta feminista de análise de espetáculos. Dissertação (Mestrado em Artes - Teatro) - Unesp, São Paulo, 2017.

CANCIONERO. Dilemma, un espectáculo diferente. In: Cancionero. 05 de Janeiro de 2006. Disponível em: https://cancionero.net/dilemma-un-espectaculo-diferente/. Acesso em: 24 set. 2018.

CARTER, Erica. Translator Foreword. In: HAUG, Frigga (org.). Female Sexualization: A collective work of memory. Trad. Erica Carter. London; New York: Verso, 1999. p. $11-19$.

CIA KIWI. Dossiê Carne. São Paulo: Cia. Kiwi, 2015. Disponível em: http://www. kiwiciadeteatro.com.br/wp-content/uploads/2017/04/Dossie_Carne_2015.pdf. Acesso em: 24 set. 2018.

COMISSÃO DA VERDADE - SP. Cap. III - As ações judiciais das Famílias Teles e Merlino/ Parte III - Ações de resistência e medidas de justiça e transição/ Tomo I - Recomendações gerais e recomendações temáticas. In: Relatório da Comissão de Verdade do Estado de São Paulo "Rubens Paiva". São Paulo: Plataforma Verdade Aberta. Disponível em: http://comissaodaverdade.al.sp.gov.br/relatorio/tomo-i/ parte-iii-cap3.html. Acesso em: 24 set. 2018.

CRUZ, Bianca Bogianni. A relação entre teatro e expectação numa proposição feminista: os casos de duas peças exclusivas para mulheres no Brasil. Dissertação (Mestrado em Artes - Teatro). Unesp, São Paulo, 2018.

DOLAN, Jill. Presence and Desire: essays on gender, sexuality, performances. Michigan: University of Michigan Press, 1993.

GARCIA, Lauro Lisboa. Assunto proibido. Revista Época Online, 13 dez. 2010. Coluna Mente Aberta. Disponível em: http://revistaepoca.globo.com/Revista/ Epoca/0,EMI156994-15220,00-ASSUNTO+PROIBIDO.html. Acesso em: 25 set. 2018.

GOODMAN, Lizbeth. Contemporary Feminist Theatre: to each her own. London; New York: Routledge, 2005.

GUIRRA, Rafael. Regina Braga em Um Porto para Elizabeth Bishop. Blog Recanto Adormecido, 5 dez. 2011. Disponível em: http://recantoadormecido.com. br/2011/12/05/regina-braga-em-um-porto-para-elizabeth-bishop. Acesso em: 24 set. 2018.

HAUG, Frigga. Beyond female masochism: memory work and politics. Translated by 
Rodney Livingstone. London; New York: Verso, 1992.

HAUG, Frigga (org.). Female Sexualization: A collective work of memory. Translated by Erica Carter. London; New York: Verso, 1999.

MARQUES, Maurício Cundari. Teatro traz reflexão sobre o aborto. Semanário.com.br, out. 2014. Disponível em: http://www.semanario.com.br/noticia/2014/10/teatrotraz-reflexao-sobre-o-aborto/10800. Acesso em: 24 ago. 2018.

MELO, Dayana. Roteiro da Peça de Teatro: Gravidez na Adolescência. Blog Dayana Melo, 10 jun. 2011. Disponível em: http://dpachecomelo.blogspot.com/2011/06/ peca-de-teatro-gravidez-na-adolescencia.html. Acesso em: 24 ago. 2018.

MOREIRA, Andrea. Navegações estéticas - atriz Fernanda Azevedo. Vimeo, 2018. Disponível em: https://vimeo.com/263150786. Acesso em: 8 mar. 2019.

MORENO, Newton. A máscara alegre: contribuições da cena gay para o teatro brasileiro. Revista Sala Preta, São Paulo: ECA/USP, v. 2, p. 310-317, 2002. Disponível em: $\quad$ www.revistas.usp.br/salapreta/article/viewFile/57108/60096+\&cd=12\&hl=pt$B R \& c t=c l n k \& g l=b r$. Acesso em: 24 set. 2018.

MOTA, Keli Rocha Silva. Feminismo contemporâneo: como ativistas de São Paulo compreendem uma terceira onda do movimento no país. Revista Extraprensa: Cultura e Comunicação na América Latina, São Paulo: USP, v. 11, n. 1, p. 108-127, 2017. Disponível em: http://www.revistas.usp.br/extraprensa/article/view/139729. Acesso em: 1 mar. 2019.

NATARELLI, Natália. Morro como um país: "a arte deve responder ao perigo de uma época". Carta Maior - O Portal da esquerda. 31 mar. 2014. Disponível em: https://www.cartamaior.com.br/?/Editoria/Arte/Morro-como-um-pais-a-arte-deveresponder-ao-perigo-de-uma-epoca-/39/30621. Acesso em 24 set. 2018.

NEPOMUCENO, Tamires. A difícil escolha. Site Teatro Cristão, [s.d.]. Disponível em: http://teatrocristao.net/texto/a_dificil_escolha. Acesso em: 24 ago. 2018.

OLIVEIRA, Samir. Amelinha Teles e a incansável luta contra o machismo: dos anos 1960 aos dias de hoje. Sul 21, 25 nov. 2013. Disponível em: https://www.sul21.com. br/ultimas-noticias/politica/2013/11/amelinha-teles-e-incansavel-luta-contra-omachismo-dos-anos-1960-aos-dias-de-hoje/. Acesso em: 25 ago. 2018. 
PAIVA, Marcelo Rubens. Vange Leonel estréia peça sobre lésbicas dos anos 20. Jornal Folha de São Paulo Online, São Paulo, 20 jun. 2000. Ilustrada. Disponível em: https://www1.folha.uol.com.br/fsp/ilustrad/fq2006200007.htm http://meusolsticio. blogspot.com/2009/01/sereias-da-rive-gauche.html. Acesso em: 24 de set. 2018.

ESPETÁCULO Confissões de Adolescentes em Angra dos Reis. [S. I., s. n.], 2009. 1 vídeo (2 min). Publicado pelo canal Perfil da Região. Disponível em: https://www. youtube.com/watch?v=fpzECSog6vE. Acesso em: 24 set. 2018.

ROCHA, Bruna; AZEVEDO, Isabelle. Nem presentes, nem congratulações: 8 de março é dia de luta! Marcha Mundial das Mulheres, 11 mar. 2014. Disponível: https:// marchamulheres.wordpress.com/2014/03/11/veja-como-foram-as-mobilizacoesda-mmm-neste-8feminista-por-todo-o-brasil/. Acesso em: 24 Set. 2018.

ROCHA, Daniela. "Violeta Vita" disseca ardente paixão feminina. Jornal Folha de São Paulo Online, São Paulo, 14 set. 1995. Ilustrada. Disponível em: https://www1.folha. uol.com.br/fsp/1995/9/14/ilustrada/18.html. Acesso em: 24 set. 2018.

SCHAPIRA, Cláudia. A dramaturgia e a encenação em Orfeu Mestiço. Revista Sala Preta, São Paulo: ECA/ USP, v. 12 n. 1, Dossiê Espetáculo, p. 181-193, 2012. Disponível em: https://www.revistas.usp.br/salapreta/article/view/57560/60614. Acesso em: 28 set. 2018.

SCHAPIRA, Claudia. Memória Impressas-Caderno deTrabalho. São Paulo: CCSP, 2015. Disponível em: http://centrocultural.sp.gov.br/site/wp-content/uploads/2014/05/ MEMORIAS_IMPRESSAS.pdf. Acesso em: 28 set. 2018.

TELES, Maria Amélia de Almeida. A construção da memória e da verdade numa perspectiva de gênero. Revista Direito GV, São Paulo: GV, v. 11, n. 2, p. 505522, dez. 2015. Disponível em: http://www.scielo.br/scielo.php?script=sci_ arttext\&pid=S1808-24322015000200505\&lng=en\&nrm=iso. Acesso em: 10 mar. 2019.

ZIRBEL, Ilze. Estudos de gênero e estudos feministas no Brasil:um debate. Dissertação (Mestrado em Sociologia Política) - Programa de Pós-Graduação em Sociologia Política, Universidade Federal de Santa Catarina, Joinville, 2007. Disponível em: $\quad$ https://repositorio.ufsc.br/bitstream/handle/123456789/90380/241321. pdf?sequence. Acesso em: 25 set. 2018. 